\title{
Educación y movimientos de protesta: Autodescripciones desde el Estado sobre las nociones de libertad en el Chile contemporáneo
}

\author{
Education and Protest Movements: Self- Descriptions from the State \\ about the Notions of Freedom in Contemporary Chile
}

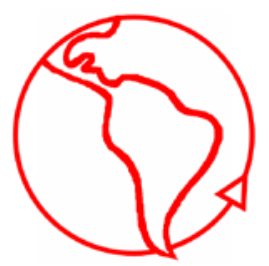

\section{Felipe Rivera}

Vicerrectoría de Investigación y Desarrollo, Universidad de Concepción, Chile

\section{Jorge Cárcamo}

Estudiante de Magíster en Análisis Sistémico Aplicado a la Sociedad, Universidad de Chile

\section{Carlos Carrasco}

Facultad de Ciencias Sociales, Universidad de Concepción, Chile

\section{José Miguel Hoyos}

Facultad de Ciencias Sociales, Universidad de Concepción, Chile

\section{Dusan Cotorás}

Facultad de Ciencias Sociales e Historia, Universidad Diego Portales, Chile

\section{Resumen}

\begin{abstract}
El siguiente artículo se orienta a elaborar un abordaje pormenorizado, desde los recursos conceptuales brindados por la Teoría de los Sistemas Sociales Autopoiéticos desarrollada por Niklas Luhmann, sobre la deriva semántica que ha evidenciado la noción de libertad, en base a las principales reformas acontecidas desde el aparato público sobre el ámbito educacional. A partir de lo anterior, hemos seleccionado cuatro periodos históricos que revisten una particular cuota de importancia para el desarrollo del análisis, en cuanto nos permiten observar las variaciones de mayor significación en los marcos regulatorios que encuadran la idea de libertad ya mencionada. Asimismo, hacemos hincapié en la efervescencia de los movimientos de protesta ligados a las demandas estudiantiles, en tanto nos permiten vislumbrar desvíos e irritaciones comunicativas que tienden a interpelar al andamiaje estatal. Según tales premisas, enfatizaremos los mecanismos con que el Estado ha procesado tales demandas sociales, considerando para esto, sus autodescripciones en materia del rol que le compete, las regulaciones que ha enarbolado y las tematizaciones de los aspectos relevantes en el discurso de los movimientos de protesta.
\end{abstract}

\section{Palabras Clave: Semántica/ Estructura Social; Educación; Estado; Movimientos de} Protesta; Libertad Negativa

\begin{abstract}
The following article aims to elaborate a detailed approach, from the conceptual resources provided by the Theory of Autopoietic Social Systems developed by Niklas Luhmann, about the semantic drift that has highlighted the notion of freedom, based on the major reforms that occur from the public apparatus in relation with the educational field. From the above, we have selected four historical periods that represents particular importance for the development of the analysis, as they contribute to observe the most significant changes in the regulatory frameworks
\end{abstract}


that fit the idea of freedom mentioned above. Likewise, we emphasize the effervescence of the protest movements linked to student demands, while they allow us to contemplate detours and irritations that tends to interpellate the state scaffolding. According to these premises, we will denote the mechanisms with which the State has processed such social demands, considering for this, their selfdescriptions of his role, the regulations that has raised and the theming of the relevant aspects in the discourse of protest movements.

Keywords: Semantic/ Social Structure; Education; State; Protest Movements; Negative Freedom

\section{Introducción}

La sucesión de reformas estatales que se han orientado hacia el sistema educacional en Chile, desde el año 1973 hasta la actualidad, han reflejado un encadenamiento de transformaciones en torno a los proyectos educacionales que ha buscado oficiar el aparato público. La variación señalada responde, de igual forma, a la orientación ideológica de los gobiernos de turno. De esta manera, es posible distinguir una impronta liberal en el campo educacional, como también, la introducción de un sello abiertamente nacionalista, una vez que los militares acceden al control del Estado.

Las interpretaciones disponibles sobre el tema tienden a generalizar la semántica que moviliza la protesta estudiantil a otros ámbitos de la sociedad sin tomar en consideración la opacidad y el procesamiento diferenciado de las instituciones a las que se dirige el discurso crítico. Esta confusión de niveles puede resolverse explicitando en el análisis empírico, el sistema de referencia encargado de procesar estas discrepancias sin caer en la tentación de trasladar nuestras observaciones a los actores sociales movilizados. En este sentido, los avances en la teoría de la evolución sociocultural desarrollados por el sociólogo alemán Niklas Luhmann (1998; 2007), pueden iluminar el ámbito no observado en las descripciones disponibles, indicando con precisión el rango de relaciones posibles que permiten enlazar una decisión política con la siguiente, sin asumir una correspondencia punto por punto con los estímulos provenientes de su entorno.

Si este continuo de reformas políticas es concebido desde el punto de vista sistémicoluhmanniano, podemos generar una apertura analítica en los siguientes términos: cada hito de importancia para el campo educacional puede ser conceptuado mediante los recursos que brinda la observación de segundo orden. En consecuencia, las distinciones elaboradas en cada período responden a dos elementos centrales: por un lado, a una línea de base que se entronca en la idea-fuerza de la libertad, mientras que por el otro, a un condicionamiento surgido desde la coyuntura socio- política por la que atravesaba el país.

Por lo tanto, hemos considerado cuatro periodos históricos para la formulación de nuestro análisis, a saber: i) un primer periodo del régimen militar, el que se enmarca entre el año 1973 y el 1980; ii) un segundo periodo del régimen militar, encuadrado entre 1980 y 1990; iii) la administración concertacionista de Michelle Bachelet, emplazada entre el año 2006 y el 2010, y iv) el gobierno de Sebastián Piñera, comprendido desde el 2010 hasta la actualidad. A partir de lo mencionado, la elección de estos ciclos políticos se justifica en base a la transcendencia de las reformas que cada uno de estos hitos manifestó en términos educacionales, como también, su relación con los movimientos de protesta, en la medida que revistieron una particular cuota de pujanza para el tránsito histórico del Estado en cada una de las fases indicadas.

De acuerdo a esta selección, haremos hincapié en tres dimensiones: expectativas, regulaciones y movimientos de protesta. A su vez, estas se orientan, respectivamente, a: visibilizar el modelo ideal de Estado predominante en cada entramado histórico; las medidas que se condujeron a consolidar dicho ideal; y las observaciones desplegadas 
sobre la emergencia de los movimientos de protesta, en tanto que evidenciaron las tendencias y demandas que la sociedad civil manifiesta en torno al ámbito educacional. Estas dimensiones pueden verse reflejadas mediante las siguientes interrogantes: en lo alusivo a las expectativas, nos preguntamos por cuál es rol que desempeña el Estado; a nivel de las regulaciones, nos interesa dilucidar cómo cumple ese rol el aparato estatal; y en lo concerniente a los movimientos de protesta, nos centramos en cómo observa el estado a los movimientos de protesta.

Quisiéramos enfatizar que el punto nodal del siguiente análisis, corresponde a la existencia de un substrato que, a pesar de todas las reformas efectuadas, permanecería en una condición latente. En virtud de lo anterior, este concepto estaría imbricado en una noción de libertad históricamente constituida que, a pesar de todas las intervenciones constatadas, habría logrado la conformación de un núcleo duro indefectible. En efecto, para el abordaje de dicha noción tendremos como referencia la siguiente interrogante: ¿qué tipo de libertad prima según cada período histórico en cuestión?

De acuerdo a lo expuesto, el presente artículo consideró la utilización de las siguientes fuentes: documentos oficiales, como los mensajes presidenciales del 11 de septiembre y 21 de mayo, la Declaración de Principios del Gobierno de Chile de 1974 y comunicados de prensa oficiales. Por su parte, también fueron incluidos en la revisión, prensa de la época y literatura especializada.

Finalmente, y aceptando con Luhmann que las demandas del entorno solo adquieren sentido cuando encuentran condiciones de plausibilidad en estructuras altamente diferenciadas, tendremos a centrar nuestra atención en las modalidades que admite el concepto de libertad para transformar el ruido no-codificado de su ambiente en una información comprensible. Se trata de concebir la deriva estructural de un concepto que le ha permitido al Estado planificarse a sí mismo frente a las turbulencias de un entorno inestable. Para comprender entonces el devenir que ha llevado a la mantención/modificación de la idea de libertad a lo largo de las últimas décadas, presentaremos en primera instancia las innovaciones conceptuales que introduce Luhmann para observar las relaciones entre estructura social y semántica, y en segundo lugar, los mecanismos que permiten coordinar su evolución de manera conjunta, para problematizar las estructuras sociales que favorecieron el surgimiento de la noción de libertad y su evolución en el tiempo.

\section{Evolución socioestructural de la semántica: La relación entre semántica y estructura social}

\subsection{La teoría de la evolución sociocultural desde la perspectiva de Niklas Luhmann}

La teoría de la evolución desde la teoría de sistemas sociales no debe confundirse con la búsqueda de estadios de desarrollo, teleologías o relaciones de causalidad lineal. La evolución no supone progreso sino el despliegue de condiciones recursivas que habilitan la emergencia de lo imprevisto a partir de lo previsible. En otras palabras, "la evolución transforma la baja probabilidad del surgimiento en una alta probabilidad de la preservación" (Luhmann 2007: 326). El presupuesto es esta paradoja, que asume la existencia de sistemas autorreferenciales limitados por su estructura, y que para modificar sus operaciones deben recurrir a sus propias operaciones (Luhmann \& De Giorgi 1993).

Sobre la base de estos supuestos, el Estado moderno logra diferenciar sus propias operaciones de los acontecimientos, interpelaciones o decepciones provenientes de su entorno. Estas potenciales irritaciones pueden incorporarse accidentalmente en los recursos semánticos que utiliza el Estado para justificar sus operaciones solo en la medida que adquieran sentido en las expectativas del sistema político. Nuestro análisis sobre los 
aspectos que subyacen a las modificaciones en la normativa estatal tendrá que delimitar entonces un nivel semántico, y un nivel estructural, así como las formas de entrelazamiento y condiciones históricas que promovieron su dinamismo.

\subsection{Relación entre semántica y estructura social}

La semántica y la estructura social se conciben como "formas de ordenamiento" o condensaciones generalizadas de sentido que dan origen a expectativas en la sociedad (Luhmann 1991). Su función principal consiste en orientar la comunicación otorgándole un marco donde adquiere sentido. La diferencia entre ambas se puede graficar de mejor manera si nos concentramos en la distinción entre operación y observación. La estructura se desenvuelve en el nivel operativo, donde el sistema se reproduce mediante la diferenciación con su entorno. La estructura social aporta un conjunto de presupuestos que permiten relacionar los elementos (comunicaciones) dentro de un sistema mientras que la observación sobre esas relaciones se describe en el nivel semántico. Así, la semántica ofrece una reserva de temas que permiten distinguir y otorgar sentido a las transformaciones de la sociedad que de otra manera solo podrían presuponerse (Blanco 2011).

Tanto la estructura social como la semántica evolucionan en conjunto (Luhmann 2007). La relación entre ambas podría pensarse como los dos lados de una misma forma, puesto que sin las descripciones en el nivel semántico no se podrían poner a disposición de la comunicación las interpretaciones sobre cambios que ocurren a nivel operativo. Por lo mismo, la velocidad con que emergen los artefactos semánticos es siempre posterior a la formación de estructuras, en tanto requieren de un mayor grado de sedimentación, a diferencia de la inmediatez de las operaciones autopoiéticas ${ }^{1}$. Aclarando este punto, podemos estudiar la diferencia entre el nivel operativo y semántico como un diferencial susceptible de proveer herramientas heurísticas para la descripción de lo emergente a partir de lo que ya existe, o al menos lo que permanece presupuesto como estructura del sistema.

En este sentido, la estructura social se mantiene en un mayor nivel de abstracción que solo puede concretizarse y actualizarse por medio de nuevas auto-descripciones que sustituyan a las anteriores (Blanco 2011). La observación de las semánticas nos permite entonces delinear una oportunidad de observación empírica sobre los cambios en la estructura social focalizándonos precisamente en el análisis de la variabilidad de un concepto y su relación con los cambios a nivel operativo. La coordinación entre los cambios experimentados entre la estructura social y la semántica están mediadas por la definición de tres mecanismos encargados de procesar el grado de sedimentación que adquiere un concepto bajo condiciones de evolución autorreferencial, a saber: mecanismos de variación, selección y restabilización (Luhmann 2007).

\subsection{Cambio estructural y mecanismos evolutivos}

Luhmann (1991) relaciona cada mecanismo encargado del procesamiento evolutivo con los componentes de la autopoiesis del sistema, es decir, elementos (variación), estructura de expectativas (selección) y sistema de referencia (restabilización). La probabilización del hecho improbable de que una nueva concepción de libertad se acepte tiene que ver precisamente con la diferencia entre variación y selección. Dicho de otra manera, en el valor estructural que se le asigna a una comunicación novedosa. Según Luhmann (2007: 358), "la variación consiste en una reproducción desviante de elementos por elementos del sistema (...) consiste en una comunicación inesperada, sorprendente". En este sentido,

\footnotetext{
${ }^{1}$ Para una crítica a la tesis de la "posterioridad constitutiva" de la semántica, se recomienda consultar la propuesta de Urs Staeheli (2000).
} 
una variación siempre es la negación de una estructura preexistente, es decir, es una oportunidad de apartarse de las comunicaciones que vienen reproduciéndose con regularidad. Sin embargo, las desviaciones son seleccionadas por las estructuras de un sistema. Solo algunas son dignas de conservarse mientras que el resto permanece como episodio aislado y se olvida rápidamente.

Para que una variación sea seleccionada debe encontrar condiciones de plausibilidad en las estructuras de expectativas que permitan condensar su significado como autodescripción. De esta manera el segundo mecanismo evolutivo "elige las referencias de sentido que tengan valor de formar estructuras, idóneas para el uso repetido, capaces de construir y condensar expectativas" (Luhmann 2007: 358). A partir de una comunicación desviante se abre la posibilidad de ser seleccionada y generar una alternativa estructural que amplifique la variación inicial haciendo eco en alguna expectativa del sistema. Precisamente el tercer mecanismo, de restabilización, supone la integración de esa primera comunicación como una guía estable para las comunicaciones subsiguientes, a las que el sistema deberá poner a prueba ante nuevas oportunidades de variación.

Bajo condiciones de ejecución de la diferenciación funcional de la sociedad, la aceptación de estas variaciones se probabiliza gracias a la codificación de cada sistema frente a las inestables ofertas de sentido en el entorno (Luhmann 1993). Podemos hablar de evolución cuando las irritaciones del entorno permiten reconfigurar respuestas en las estructuras de expectativas transformando las ya existentes. En síntesis, los mecanismos de selección permiten introducir oportunidades de selección, que pueden ser aceptadas o no, por el sistema de referencia. Esta variación puede llegar a ser seleccionada condensándose como semántica disponible para orientar la comunicación. Y finalmente la restabilización en las estructuras del sistema supone la emergencia de estructuras diferenciadas que incorporen esa variación en los presupuestos de sus operaciones.

Consideraremos entonces para el análisis empírico del devenir histórico del concepto de libertad, distintos contextos de estabilización frente a episodios conflictivos a nivel institucional y de opinión pública. Específicamente nos concentraremos en los recursos semánticos que utiliza el Estado para describir su rol dentro de la sociedad, la manera en que se estabilizan dichas atribuciones en regulaciones de orden normativo y por último, el procesamiento de potenciales desviaciones reconocidas en la comunicación de protesta.

\section{Dimensiones de análisis: Expectativas, regulaciones y movimientos de protesta}

\subsection{Primer periodo del régimen militar (1973-1980)}

\section{a) Rol del Estado}

Las expectativas en torno al Estado nos indican que una vez realizado el golpe de Estado, surgió una necesidad de reinstaurar el orden sociopolítico al país. Como sabemos, el período gubernamental de Salvador Allende significó para las fuerzas armadas una ruptura con la tradición liberal construida, en gran medida, por las administraciones radicales. Asimismo, la ideología marxista era considerada como un agente disolvente de los principios institucionales de Chile, pero, sobre todo, del ideal de la nación.

De esta forma, la Junta de Gobierno plasmó con claridad, en sus planeamientos gubernamentales, la defensa y preservación de la nación como deberes irrenunciables (Mensaje Presidencial 1973). Para los militares, la nación constituye una idea-fuerza de valor inestimable; según su marco ideológico, este concepto posee la cualidad de cohesionar a la población y de orientar el devenir social. En consecuencia, la presencia castrense en el aparato público se justifica ante la amenaza marxista, que habría comprometido la autonomía del país en relación a una eventual inclusión en la esfera 
política de la Unión Soviética. En este sentido, el gobierno militar centra sus esfuerzos en aras de recuperar la capacidad de autodeterminación de los chilenos, y de superar la crisis promovida por la administración socialista (Arriagada 1981).

Otra expectativa atribuida al rol ideal del Estado, es la recuperación moral y material de todos los campos de la vida social. El aparato público debe encauzar al país hacia la paz generalizada, además de superar definitivamente la animadversión entre compatriotas. La estabilización de la sociedad solo es posible gracias al respeto a las jerarquías, lo cual señala una etapa de coerción física, necesaria para la normalización jurídica en la esfera política del país. En este contexto, la estabilización de la convivencia nacional es una situación posible mediante la erradicación de elementos ideológicamente contrarios a la tradición histórica del aparato estatal.

Una vez que las bases sociales, culturales y económicas vuelvan a su normalidad, el Estado estaría en condiciones de procesar las temáticas de mayor relevancia para el país. En el caso de la educación, los militares retoman la senda liberal recorrida por los radicales, pero, imprimiendo un sello basado en el fortalecimiento de un espíritu de disciplina, que garantice el progreso y el desarrollo armónico del país. Asimismo, surge una extrapolación de la idea relativa a la autonomía nacional, pero reenfocada en la libertad individual. Cada chileno representa un componente esencial e indispensable para el destino nacional, y en esta medida, la educación, dispensada por el Estado, debe velar por la entrega de todas las condiciones y herramientas necesarias para su plena autorrealización (Mensaje Presidencial 1973; 1974).

\section{b) Regulaciones del Estado}

En lo que concierne al ámbito de las regulaciones llevadas a cabo por el aparato público, con el objetivo de establecer un ideal de Estado, el Régimen Militar se caracterizó por elaborar un primado argumentativo que aunara los elementos centrales de su impronta nacionalista, lo que se vio reflejado en la "Declaración de Principios del Gobierno de Chile", publicada el 11 de marzo de 1974. A partir de lo anterior, se buscaba consolidar el fortalecimiento de un Proyecto Nacional que versara sobre la imagen genuina del ser de la patria y el alma del pueblo, atribuyéndole un rol subsidiario al Estado en todas sus esferas y márgenes de acción. Por su parte, y en base a dichos lineamientos, la Junta Militar se orientó a fomentar el establecimiento de un "gobierno autoritario, impersonal y justo" (Declaración de Principios del Gobierno de Chile 1974: 6), el que a su vez, se encontraba enraizado al principio de la autoridad y el resguardo del orden público. Ahora bien, cabe señalar que todas estas premisas se encontraban subsumidas en un orden jurídico basado en los derechos humanos y fundamentado en lo que el Régimen Militar definió como un respeto indefectible hacia la dignidad espiritual de las personas y sus derechos como tales.

Frente a tal escenario, se observó una acelerada promulgación de leyes, decretos, normas y reglamentos, que reconocieran el derecho a la propiedad privada y a la libre iniciativa económica, como principios rectores de la sociedad chilena, toda vez que esta no se distanciara de valores tales como la justicia e igualdad ante la ley, al mismo tiempo que, de aquellos ligados con la importancia del trabajo para el desarrollo del país y el esfuerzo personal como base de la moral ligada al mérito (Mensaje Presidencial 1974).

Por otro lado, se evidenció una reestructuración y reorganización de los distintos ministerios, toda vez que la labor de coordinar y supervisar sus planes de acción e intervenciones programáticas recaía en la cartera del interior. Fruto de esto, se llevaron a cabo numerosos diagnósticos sobre las falencias que estaban presentes en el andamiaje público del Estado chileno, los que se reconocían como herencias obsoletas de las medidas adoptadas por la Unidad Popular y el gobierno socialista de Salvador Allende (Villalobos- Ruminott 2008). Con atención en tal diagnosis, la Junta Militar se orientó a 
problematizar distintas temáticas sociales desde un enfoque nacionalista, motivo por el cual, consideró a la educación como un ámbito necesario de intervenir. En tal sentido, se desarrolló una Política Educacional en concordancia con el principio de la renovación continua, propia del quehacer educativo, que se buscaba instalar en los cimientos del país (Santa Cruz y Olmedo 2012).

Por ende, se elaboró un currículum de enseñanza básica y media acorde a los lineamientos establecidos desde el Ministerio de Educación Pública, lo que se vio acompañado de una intromisión directa de la Junta de Gobierno sobre las entidades universitarias, especialmente, cuando estas ofrecían carreras que pregonaban visiones contrarias al proyecto nacional, entre las que se sindicaron aquellas pertenecientes a las Ciencias Sociales y las Humanidades (De la Cruz 2006).

\section{c) Observación de los movimientos de protesta}

Con atención en la relevancia de los movimientos de protesta, en tanto canalizan, habitualmente, las demandas y opiniones de la sociedad civil, y que en nuestro caso se enmarcan en el ámbito educacional, se puede identificar el siguiente panorama: una impronta estatal fundamentada en la construcción de un enemigo interno en el país, lo que se tradujo en una persecución y desarticulación de toda agrupación o manifestación política que se mostrase opositora al ideario del Régimen Militar, las que eran imputadas por el modo en que buscaban desquiciar el sentido de la autoridad mediante el fomento del desorden colectivo (Mensaje Presidencial 1975).

En función de esto, se generó una ruptura en la institucionalidad democrática, concebida a partir del binomio entre oficialismo y oposición. Con ello, se distorsionaron las operatorias tradicionales de los movimientos sociales y se atomizó las capacidades transformativas de la Sociedad Civil, en especial, sus facultades para levantar demandas que interpelaran al Estado (Retamozo 2009).

A su vez, hubo un paulatino incremento, y diversificación, de los mecanismos represivos a los que el Estado apeló como estrategia basal contra las protestas sociales y actos de subversión, articulando de este modo, una violencia sistemática que impregnaba todos los ámbitos de la esfera pública. En consecuencia, se profirieron múltiples acciones persecutorias según la existencia de "agentes exteriores", capaces de propiciar escenarios de inestabilidad política, especialmente, a través de alianzas internacionales con bloques simpatizantes de la ideología marxista (Mensaje Presidencial 1976; 1977). Sin perjuicio de lo anterior, la Junta Militar legitimó institucionalmente distintas manifestaciones en agradecimiento a las Fuerzas Armadas, con motivo de su intervención en el gobierno socialista encabezado por Salvador Allende. De igual modo, se ensalzaron públicamente los actos conmemorativos del 11 de Septiembre, los que fueron en su mayoría, organizados y patrocinados por federaciones estudiantiles, agrupaciones juveniles, gremiales e instituciones de la producción y el comercio. En esta misma lógica, se aprobaron distintas marchas en apoyo al Gobierno Militar, como aquella denominada de las "cacerolas vacías".

En materia educativa, el Régimen Militar llevó a cabo una jibarización de toda organización de corte político que estuviese reñida con las autoridades gobernantes, sobre todo, en las instancias referidas al diseño de políticas educacionales, y en particular, los programas curriculares de enseñanza (Assaél et al. 2011).

\section{d) Concepto de libertad}

La concepción de libertad que surge en el período de la Junta Militar, enmarcada entre 1973 y 1981, se caracteriza por reflejar un contexto histórico signado por una extremada 
polarización social. De esta manera, la definición de este concepto es posible solamente en función de la coyuntura señalada. Por lo tanto, hay que tomar en cuenta, la intrusión de los militares en el Estado. A continuación, se deben considerar los componentes ideológicos, que nos permiten visibilizar la forma en que los militares desarrollan un entendimiento propio acerca de la de libertad (Mensaje Presidencial 1973).

Desde el punto de vista castrense, la "doctrina comunista", señala un cuerpo de ideas ajeno y nocivo a la historia del país, debido a que está profundamente reñido con el ideal relativo al ciudadano republicano, caracterizado por su autonomía, y una participación política consciente en la comunidad nacional. A partir de lo anterior, el comunismo también es interpretado como la ideología responsable de promover el quiebre entre compatriotas, y de intentar llevar a Chile hacia la desintegración. Este sistema de pensamiento es igualmente peligroso en cuanto tiende a llevar al país al interior de la órbita Soviética, y así anular la capacidad de autodeterminación nacional. Finalmente, la inestabilidad presente en los últimos años de la Unidad Popular, se considera una resultante del accionar persistente, e intencionado, de cuadros políticos declaradamente anti-nacionalistas. Es así que, el marxismo representa un término alarmante para la visión nacionalista de la Junta Militar, pues tendería a disolver los lazos fraternales entre los chilenos, necesarios para la cohesión social (Vial 1998).

Como hemos señalado, las intervenciones en el aparato público a partir de 1973, pueden comprenderse a partir del rechazo visceral hacia todo asomo de estatismo socialista, que estaría representado en el gobierno ya defenestrado (Arriagada 1981). Luego, la gran mayoría de las políticas públicas, consignadas en los discursos del 11 de septiembre, reflejan claramente el mismo contexto sociopolítico, y por consiguiente, tienden al fomento de conceptos dimanados de una "libertad negativa". Esta última idea nos indica que, la libertad siempre está condicionada frente a un polo conceptual contrario, que en este caso, está firmemente enraizado en el gobierno socialista de Allende. La libertad, entonces, se configura como la base conceptual - el substrato- de las políticas elaboradas por la Junta Militar, que habrían de contrarrestar y minimizar el impacto de las intervenciones socialistas, destacadas por la búsqueda de una homogeneización forzada sobre toda la población, y que de igual manera, habrían pretendido la anulación de principios articuladores de la cohesión social, como la propiedad privada y la plena autonomía individual.

En consecuencia, identificamos un esquema basado en la distinción "libertad/libertinaje moral y político" el que responde directamente al contexto descrito. Este último se refiere a la visión militar acerca de la libertad, como también, a la desnaturalización del concepto en manos de la Unidad Popular. Por un lado, tenemos una noción que busca la promoción de una nación libre, que a su vez, esté integrada por individuos emancipados de toda doctrina internacionalista, mientras que por el otro, el caso del comunismo-socialismo, que habría llevado al país a una situación anómica, donde el Estado de Derecho habría dejado de operar, fomentando una profunda crisis estructural, que finalmente generó la polarización social e ideológica ya comentada.

En función de lo anterior, la siguiente tabla resume las principales dimensiones del ciclo histórico en cuestión: 
Tabla 1: Primer periodo del régimen militar (1973-1980)

\begin{tabular}{|c|c|c|c|}
\hline $\begin{array}{c}\text { Expectativas en } \\
\text { torno al Estado }\end{array}$ & $\begin{array}{c}\text { Regulaciones } \\
\text { estatales }\end{array}$ & $\begin{array}{c}\text { Observación de los } \\
\text { movimientos de } \\
\text { protesta }\end{array}$ & $\begin{array}{c}\text { Concepción de } \\
\text { libertad }\end{array}$ \\
\hline $\begin{array}{c}\text { Refundación del } \\
\text { ideal de la nación }\end{array}$ & $\begin{array}{c}\text { Emergencia de un } \\
\text { rol 'subsidiario' del } \\
\text { Estado en } \\
\text { contraposición a } \\
\text { uno de } \\
\text { 'compromiso' }\end{array}$ & $\begin{array}{c}\text { Anulación del } \\
\text { potencial político de } \\
\text { los movimientos de } \\
\text { protesta }\end{array}$ & $\begin{array}{c}\text { Libertad/ Libertinaje } \\
\text { moral y político }\end{array}$ \\
\hline
\end{tabular}

Fuente: Elaboración propia

\subsection{Segundo periodo del régimen militar (1980-1990)}

\section{a) Rol del Estado}

Contextualizando el segundo periodo de Pinochet, se distingue una legitimación por parte del régimen, a través de la constitución de 1980 - con Pinochet en la figura de Presidenteque delineará a futuro la relación entre la ciudadanía y el Estado. La constitución, de carácter presidencialista fuerte o autoritario, es el correlato a los valores subyacentes del régimen: libertad, seguridad, progreso y justicia como una distinción a lo que denominan anti-valores: totalitarismo, estatismo, terrorismo, violencia subversiva y demagogia. A través de esta figura, el ideal de democracia observado por el régimen, es el que debe distinguirse de una neutralidad democrática, pues, la neutralidad permite en sí misma el aprovechamiento de los enemigos de la democracia, tal como sucede antes de 1973 (Revista Realidad 1980:2)

Por ello, el sentido de la constitución, como proyecto de visión de sociedad, es el defender la libertad radicada en el individuo a través de los valores inherentes a un humanismo como emergencia del sustrato cultural de lo moderno. Así, se debe defender la matriz organizacional de la civilización occidental, defender la religión católica apostólica romana, defender el ser racional y enfatizar la igualdad de derechos ciudadanos, correspondiendo esta matriz de valores a un régimen de carácter integrista ${ }^{2}$. En tanto el individuo es libre, el Estado debe estar al servicio de él y no al revés, consagrándose la ideología en el principio de subsidiariedad como la clave de una sociedad libre (Ibíd.). La familia es proclamada como el núcleo básico de la sociedad reconociendo el Estado su autonomía frente a los cuerpos intermediarios. El Estado, en tanto su rol de Estado Subsidiario, se sitúa en los particulares que, en forma individual o agrupada en sociedades libres, no están en condiciones de realizarse en forma adecuada.

En la nueva concepción de sociedad que construye el régimen, se enfatiza las diferenciaciones semánticas de corte nacionalista - como el totalitarismo que amenaza la libertad individual de las personas- y se realza constitucionalmente el fortalecimiento del derecho y libertades de estas. Es en uno de estos derechos individuales - el derecho de los padres de educar a los hijos y el de la libertad de enseñanza- donde el rol del Estado pasa a ser un instrumento de autobservación que mide el ajuste de expectativas entre el régimen y la sociedad. Su rol se basa en la legitimación ideológica -en cuanto política- a través de la autoafirmación del modelo, y económica en cuanto al sujeto productivo. La educación es remodelada, pulida, adecuada en un sentido funcional al proyecto de sociedad donde debe hacer sentido al modelo de desarrollo basado en la libertad

\footnotetext{
${ }^{2}$ Régimen integrista es referido a la restabilización de semánticas de la modernidad antes escindidas de las lógicas del estado. Ejemplo: incidencia de la religión en la operatividad del Estado y la asimilación de lógicas castrenses en el Estado.
} 
individual, el libre mercado y el respeto a la propiedad privada en una sociedad jerarquizada y protegida. (Núñez y Vera 1988).

Esta función que asume el Estado se constata en la praxis, a través de la forma de un sistema educacional de carácter compensatorio que se corresponde, en una primera etapa de facto, con la re- estructuración llevada a cabo, la instauración de un modelo autoritario, excluyente, cuya base de legitimación recae en las fuerzas armadas (Briones et al. 1991). En una segunda etapa se corresponde con la legitimación legal a través de la constitución de 1980, en donde el régimen expresa su ruptura con el Estado de compromiso estableciendo la subsidiariedad en materia educacional, generando mecanismos de compensación ante la escisión de responsabilidades que este había predispuesto.

\section{b) Regulaciones del Estado}

Este modelamiento de la educación, con la familia como el reflejo del principio de subsidiariedad, el motor de la identidad nacional y en donde radica la verdadera libertad coartada anteriormente por un totalitarismo marxista, contrasta con la idealización de proyecto- país que diseña el régimen. En efecto, este observa que Chile perdió las virtudes que tuvo cuando regímenes conservadores y autoritarios fundaron el Estado- Nacional, por tanto un proyecto democrático socializante y de intervención estatista sería el responsable, junto con la penetración comunista, del caos que se encontraba el país en 1973. De esta manera, la educación es una entidad que debe ser corregida, pues está anarquizada: Se exacerban los ritos nacionalistas en las escuelas, los himnos nacionales, las formaciones antes de que los estudiantes ingresen a clases, entre otras cosas. Así, desde 1979 se enfoca en normalizar su funcionamiento de acuerdo al proyecto de país que el Estado quiere construir: eliminar la burocracia estatista centralizada y compatibilizarla con las verdaderas necesidades nacionales. (Guzmán 1982).

En este sentido, se readecúa la operatividad institucional y se rechaza la hipertrofia del Estado manifestado en el pesado entramado burocrático y socializante. La distinción libertad/ regulación confluyen dicotómicamente en la emergencia de una libertad negativa, pues se pregona que el Estado solo debe interferir en la libertad del individuo cuando este no tiene la capacidad de autorrealización; sin embargo es la propia ideología nacionalista la que impone límites a la libertad de enseñanza, pues la libertad no va a tener otras limitaciones que las impuestas por la moral, las buenas costumbres, el orden público y la seguridad nacional. Es de esta manera que las regulaciones impuestas por el régimen no son otras que el encauzar un sistema educativo hacia los valores nacionales antes nombrados.

En cuanto a la educación superior universitaria, las instituciones públicas fueron desmembradas y a partir de ellas se crearon nuevas universidades regionales. Se implementaron los Institutos Profesionales (IP), con carreras largas de 4 años, y los Centros de Formación Técnica (CFT), con carreras cortas de 2 años, los que además, eran todos de orientación privada.

Para caracterizar las regulaciones articuladas por el Estado, hemos establecido algunos hitos importantes para este periodo (Núñez \& Vera 1988):

I) El primer gran hito es la municipalización de la educación que ocurre desde el año de 1981 hasta el año de 1986, como parte del proceso de descentralización administrativa. El aspecto fundamental era el traspaso administrativo desde el ministerio hacia las comunas donde se ubicaban los establecimientos. La municipalización tenía como objetivo la descentralización administrativa.

II) La subvención por alumno: por medio de la entrega de un voucher o subsidio por concepto del promedio de asistencia por alumno. Esta subvención se transfiere a la figura 
del sostenedor. Su objetivo es ser un aliciente si el promedio de asistencia es alto o un castigo si el promedio es bajo.

III) La liberalización del mercado laboral de profesores: donde estos pierden su condición de empleados públicos. Esto implica la emergencia de un mercado laboral pedagógico donde la determinación de sus salarios está determinada por cada sostenedor de manera individual.

IV) El Sistema Nacional de Evaluación: uno de los mecanismos de auto observación que implementa el Estado está relacionado con la implementación de sistemas de evaluación de rendimiento. Primero el Programa de Evaluación del Rendimiento Escolar (PER.), entre 1982 y 1984, y luego el Sistemas de Medición de Calidad de la Educación (SIMCE), desde el año 1988 hasta la actualidad.

V) La reestructuración de la educación superior: desmembramiento de la Universidad de Chile y Técnica del Estado, creación de Institutos Profesionales y Centros de Formación Técnica. Disminuye el aporte del Estado a la educación superior, por lo que prima el principio de subsidiaridad para este tramo educacional, aplicando la arancelización y el esquema empresa dentro de la educación superior.

VI) La Ley Orgánica Constitucional de Enseñanza (LOCE): Fija los requisitos mínimos con que deben operar los niveles de enseñanza básica y media: dentro de los aspectos claves se destacan:

- Libertad de enseñanza: se enfatiza en el aspecto decisional de los padres y la libertad de ejercer la enseñanza. La regulación solo se remite a lo que la ley entiende por moral, buenas costumbres y ética.

- Currículum mínimo: contenidos académicos mínimos que deben cumplir los alumnos.

- Derecho: Se establece que la educación es un derecho y es el Estado quien debe resguardar en todos sus aspectos.

- Reconocimiento: es el ministerio de educación quien reconoce y les da legitimidad jurídica a los establecimientos de enseñanza básica, media y superior. Los requisitos son contar con un sostenedor y ceñirse a los planes de estudio aprobados.

- Limites: El Estado se auto- establece límites, lo que implica una reducción del campo de acción del ejecutivo para generar modificaciones y regulaciones.

\section{c) Observación de los movimientos de protesta}

Hasta 1983 los movimientos sociales seguían siendo parciales y dispersos, sin lograr un carácter masivo. La represión del régimen fue unos de los factores fundamentales en la reorganización de los movimientos sociales, pero no los únicos. En la oposición, a falta de un proyecto político unitario y alternativo al régimen, constituía el mayor escollo para la reagrupación de los partidos. Los únicos movimientos sociales visibles antes de 1983 eran la vicaría de la solidaridad y sus organizaciones asociadas, por tanto era más difícil su intervención por parte del régimen. (Guillaudat \& Mouterde 1998)

Su organización fue consecuencia de las flagrantes violaciones a los derechos humanos, las torturas y los detenidos desaparecidos. La Coordinadora Nacional Sindical, reagrupó una serie de sindicatos cercanos a la antigua CUT alrededor de un discurso combativo. Por ello, estallaron las primeras huelgas y protestas en sectores estratégicos de carácter productivo, en especial, el cobre. La figura de Tucapel Jiménez, se convierte en el primer hito con respecto a la relación del régimen y los movimientos sociales. La muerte de Jiménez - encubierta como asesinato- marca el inicio del amedrentamiento político implícito del régimen. 
La lógica, desde el punto de vista del Estado, es establecer una diferenciación entre política y ciudadanía, esto implicó en el ámbito pragmático, de las políticas del régimen, una escisión de la comunidad con las lógicas de toma de decisión. Ciudadanía ya no implica una comunidad política. El Estado establece, como un aspecto intrínsecamente positivo, la despolitización de todos los ámbitos, en especial del aspecto económico y social. El objetivo seleccionado es la disolución del sistema político como el dispositivo de oposición ideológica donde se operativizan las decisiones, dando pie al sistema electoral actual que encauza todas las decisiones en función de los preceptos y mecanismo de la constitución de 1980, el Estado construye una visión no binaria de la concepción política como oposición ideológica, pues esta oposición se visualiza como un obstáculo de los objetivos planteados por el mismo.

El Estado, al establecer esta diferenciación, genera formas de desbaratamiento y amedrentamiento político con el fin de establecer y sedimentar el principio de despolitización. Las lógicas con las que procede deben ser sigilosas, a diferencia de la época anterior. La CNI a través de las desapariciones y muertes sistematizó el amedrentamiento político de los opositores del régimen buscando evitar el repudio social, tanto interno como externo, que generaron las operaciones realizadas antes, es decir abiertas, sangrientas, pero, sin embargo, justificadas como necesarias.

En este sentido, el régimen a través de la represión y del desbaratamiento de cualquier movimiento social que fuese un peligro para su existencia, no prevé que el catalizador para la agrupación de movimientos sociales de carácter heterogéneos en la época es la emergencia de la crisis económica en los periodos de 1981- 1983. La crisis se produce en cuanto a la falla estructural económica del propio régimen en hacer frente a esta y que, contrariamente, la profundiza. Esta contingencia irrita a los movimientos sociales catalizando la primera protesta masiva con fecha 11 de mayo de 1983, sucediéndose diversas marchas posteriormente. Si bien el movimiento se articula, principalmente por el desencantamiento de las expectativas creadas por el régimen, atraviesa un espectro desde agrupaciones en todos los estratos: La clase alta con los cacerolazos y las clases más bajas (marchas y barricadas), instituyendo, por primera vez un proyecto alternativo, ciudadano y viable, al régimen. En este contexto, al régimen no le queda otra que contemporizar, realizando maniobras políticas - primero- para recuperar sectores gremiales, empresarios y sectores de derecha, y segundo, reprimiendo en concordancia de su política de seguridad nacional.

\section{d) Concepto de libertad}

La concepción de libertad con la cual opera el Estado en este periodo se conceptualiza a través de la distinción entre libertades positivas y negativas. Las libertades negativas son características de las sociedades modernas liberales y se corresponden con la autodeterminación a nivel individual. "La coacción implica la intervención deliberada de otros dentro del ámbito en cual yo podría actuar sino intervinieran" (Berlin 1988: 220). Este concepto de libertad está asociado a una contraposición frente a los colectivismos y totalitarismos externos observados como amenazas reales.

El concepto de libertad en este periodo se concibe como auto amenaza, es el propio régimen de quien emana la amenaza al concepto de libertad. En el periodo neoliberal, la libertad constituye un axioma que operativiza y prioriza todos los aspectos reflejados en la constitución de 1980. Esta funge en función de la libertad como principio axiomático de todas las demás lógicas que regula y dispone la constitución. En este sentido el establecimiento de una sociedad de libertades, entendiendo libertad como no intromisión, constituyó el modelo del Estado en esta época.

Las lógicas que emanaban del Estado configuraron su propia amenaza en base al concepto de libertad. El régimen se vio enfrentado a los preceptos que había instaurado y la 
imposibilidad de seguir operando bajo la noción de un enemigo interno al cual se debía combatir en una "guerra sucia". Sus acciones de amedrentamiento político se volvieron contraproducentes y por tanto difíciles de compatibilizar con los preceptos instaurados. La idea de neutralidad política en el sentido de desaparición de la contraposición ideológica no se podía sustentar en una sociedad que tenía un correlato seudo-democrático, al menos nominalmente. Esta situación hace necesario una fórmula que permita al Estado superar el impasse auto producido. Esto desemboca en el plebiscito de 1988 que estableció la decisión de remover o prolongar a Pinochet por 8 años más. Los resultados no se adecuaron con las expectativas del régimen, que esperaba imponerse sin problemas, esto pospuso el conflicto, sin embargo terminó con el régimen militar.

En función de lo anterior, la siguiente tabla resume los principales ejes aludidos:

Tabla 2: Segundo periodo del régimen militar (1973-1980)

\begin{tabular}{|c|c|c|c|}
\hline $\begin{array}{c}\text { Expectativas en } \\
\text { torno al Estado }\end{array}$ & $\begin{array}{c}\text { Regulaciones } \\
\text { estatales }\end{array}$ & $\begin{array}{c}\text { Observación de los } \\
\text { movimientos de } \\
\text { protesta }\end{array}$ & $\begin{array}{c}\text { Concepción de } \\
\text { libertad }\end{array}$ \\
\hline $\begin{array}{c}\text { Estado de } \\
\text { compromiso }\end{array}$ & Estado dicotómico & $\begin{array}{c}\text { Amedrentamiento } \\
\text { político }\end{array}$ & $\begin{array}{c}\text { Libertad/ } \\
\text { Autoamenaza }\end{array}$ \\
\hline
\end{tabular}

Fuente: Elaboración propia

\subsection{Gobierno de Michelle Bachelet (2006- 2010)}

\section{a) Rol del Estado}

A la largo de este periodo, se consideraba que el Estado debía transformarse en un verdadero garante de la calidad en la educación, asumiendo esta responsabilidad tanto en el sector público como privado. En otras palabras, el rol del Estado se fundamentaba en garantizar condiciones mínimas de calidad, consagrando el derecho de todo ciudadano a una educación de calidad, que no se contrapusiese a la libertad de enseñanza (Propuesta de Gobierno 2006). De este modo, el discurso estatal tematizaba la calidad educativa como parte de un "derecho ciudadano" que debía garantizarse tal como se hizo en el caso de la salud con el Plan de Acceso Universal de Garantías Explícitas (Plan AUGE). En efecto, se pretendía asegurar la igualdad de oportunidades para que el desarrollo del país se encaminara hacia una sociedad más inclusiva y equitativa (Discurso 21 de Mayo de 2006).

A nivel semántico, se buscaba plasmar una orientación hacia los valores de la democracia y el mérito individual. Asimismo, se pretendía disminuir la exclusión mediante artefactos semánticos que fortalecieran la reflexividad de las decisiones políticas, en cuanto se lograra generar mecanismos efectivos en el combate contra la desigualdad.

\section{b) Regulaciones del Estado}

Las regulaciones que se buscaban fomentar durante el Gobierno de Michelle Bachelet, se vincularon, en materia educativa, con extender la cobertura en la educación inicial - en tanto se reconocía como una etapa donde se incuban las primeras desigualdadesmediante el aseguramiento de la subvención preferencial en sectores de menores ingresos y el fortalecimiento del trabajo con los municipios como medida de descentralización. En general, las iniciativas fueron bastante modestas para la responsabilidad que pretendía asumir el Estado. Frente a petitorio que elaboraron las bases de los movimientos estudiantiles durante el año 2006, el gobierno accede a evaluar los gastos asociados a la inscripción en la Prueba de Selección Universitaria (PSU), la extensión del horario en que se rebajaba el valor del Transporte Público para el estudiantado y la ampliación de la cobertura de la alimentación escolar en jornada completa. 
Con respecto a las demandas de fondo, y por ende, de carácter estructural, se puso en marcha un Consejo Asesor Presidencial de carácter técnico y ciudadano, suponiendo la participación activa de los estudiantes y todos los actores sociales relacionados al ámbito de la educación, lo que finalmente se reflejó en el tránsito desde la Ley Orgánica Constitucional de Educación (LOCE) hacia la Ley General de Educación (LGE). En función de este contexto, se identificaron como temas de alta prioridad al currículo y las prácticas pedagógicas, los lineamientos comunes en la formación y evaluación docente, los parámetros de calidad y la continuidad entre educación media, superior y mercado laboral.

\section{c) Observación de los movimientos de protesta}

En general, el discurso del oficialismo en este periodo valoraba que los movimientos sociales, enfatizando siempre su lugar dentro de la esfera ciudadana, haya orientado la preocupación de la Sociedad Civil hacia los desafíos presente en el país en materia de educación. Este salto cualitativo se explica, en gran medida, por la codificación democrática y la observación reflexiva del sistema político, el que otorga mayores oportunidades de interpelar sus decisiones. Sin embargo, los disturbios durante las marchas estudiantiles comienzan a tematizarse como vandalismo, recordando que "la democracia se ganó con la cara descubierta" (ibíd.), y que justamente, ese debe ser el camino a seguir.

Por otro lado, se valoraba que los movimientos sociales, en tanto respondían a una forma de expresión ciudadana sobre un malestar generalizado en cuanto a la problemática educacional, no deben perder de vista que las demandas deber ser evaluadas mediante los organismos pertinentes, como es el caso del Congreso. Por lo mismo, se da paso a una suerte de deslegitimación de las demandas sostenidas por el movimiento estudiantil en el período posterior a la respuesta entregada por el Gobierno, al que se criticaba por no considerar a dicho movimiento como un interlocutor válido.

\section{d) Concepto de libertad}

En definitiva, se vislumbra que la idea de libertad educativa no puede disociarse de un condicionamiento económico, es decir, que la calidad deje de estar subordinada a la capacidad de pago de la familia. De acuerdo a esto, el aparato estatal reconocía la efervescencia que generaban las demandas estudiantiles en la población chilena como parte de su compromiso con la democracia, sin embargo, implementó soluciones únicamente a corto plazo.

En función de lo anterior, la siguiente tabla resume los principales aspectos circunscritos al periodo analizado:

Tabla 3: Gobierno de Michelle Bachelet (2006- 2010)

\begin{tabular}{|c|c|c|c|}
\hline $\begin{array}{c}\text { Expectativas en } \\
\text { torno al Estado }\end{array}$ & $\begin{array}{c}\text { Regulaciones } \\
\text { estatales }\end{array}$ & $\begin{array}{c}\text { Observación de los } \\
\text { movimientos de } \\
\text { protesta }\end{array}$ & $\begin{array}{c}\text { Concepción de } \\
\text { libertad }\end{array}$ \\
\hline $\begin{array}{c}\text { Asegurar la igualdad } \\
\text { de oportunidades }\end{array}$ & Estado garantista & $\begin{array}{c}\text { Valorización/ crimin } \\
\text { alización del } \\
\text { movimiento } \\
\text { estudiantil }\end{array}$ & $\begin{array}{c}\text { Libertad/calidad } \\
\text { subordinada al pago }\end{array}$ \\
\hline
\end{tabular}

Fuente: Elaboración propia 


\subsection{Gobierno de Sebastián Piñera (2010- Actualidad)}

\section{a) Rol del Estado}

Durante este periodo, la responsabilidad del Estado se dirige a un aseguramiento de condiciones mínimas para que el mercado reoriente su funcionamiento, en términos de las consecuencias no esperadas de sus operaciones. Los principios que definen su grado de responsabilización son los establecidos constitucionalmente, a saber a) el derecho a acceder a una educación de calidad de acuerdo al mérito; b) el derecho y deber preferente de los padres de educar a sus hijos; c) la libertad de enseñanza; y d) el deber del Estado de fomentar y garantizar proyectos educativos acordes a las necesidades particulares de la sociedad, otorgar información al respecto, respetar las decisiones de la familia y asegurar condiciones financieras básicas para la disposición de alternativas en el acceso a establecimiento educacionales. Por ende, el rol del Estado se sintetiza en una lógica de vouchers que orientan la información pertinente para la selección de alternativas educativas.

En el discurso del presidente Piñera para presentar el "Gran Acuerdo Nacional por la Educación" (GANE), este menciona lo siguiente: "aseguraremos la transparencia total del sistema y abriremos un debate amplio, para analizar la posibilidad de distinguir entre las (universidades) con y sin lucro. De acordarse la existencia de estas últimas deberán pagar impuestos por sus utilidades, los que destinaremos íntegramente al financiamiento de becas y prestamos para los alumnos más vulnerables" (Diario La Tercera, 5 de julio 2011). De esta manera, se delimitan condiciones mínimas de información sobre la calidad de instituciones educativas en el país.

Asimismo, se argumenta a favor del principio de subsidiariedad, el que a todas luces, no garantiza la movilidad social mediante los logros educativos (por ejemplo, acceder a una mejor calidad de vida por el hecho de obtener un título profesional). En consecuencia, el Estado reafirma su rol subsidiario, sin embargo, lo perfecciona ampliando la cobertura sobre la cual opera la subvención. Por otro lado, se observa que el aparato estatal insiste en recalcar que la responsabilidad de acceder a la información sobre que establecimientos educaciones presentan ventajas comparativas respecto a otros, es de plena responsabilidad de los individuos.

Como expresa el presidente Sebastián Piñera "Los estudiantes deben pensarlo 100 veces antes de elegir la universidad en la que estudian" (Tolerancia Cero 2 de Diciembre de 2012). En este sentido, la responsabilidad de la elección, aun cuando es deber del Estado garantizar al menos un mínimo de calidad de las entidades educativas, recae en las familias, y particularmente, en los propios estudiantes. Ahora bien, es importante destacar que la información que ha garantizado el Estado, presenta grandes daños. Los mecanismos que este provee para el aseguramiento de la calidad, acreditación y por tanto la determinación de las entidades de educación superior que pueden recibir subvenciones públicas, a través del crédito con aval del Estado (CAE), han estado virtualmente cooptados por grupos de interés que han generan desinformación con acreditaciones fraudulentas. Este hito genera una reestructuración de la agencia que acredita a las universidades, generando nuevas instancias de aseguramiento.

\section{b) Regulaciones del Estado}

Al interior del gobierno de Sebastián Piñera, las regulaciones estatales se entienden como la evaluación continua de las propias regulaciones. El Estado constituye instancias de evaluación de las regulaciones, en una suerte de generación continua de estándares de aprobación a través de la Agencia de la Calidad y la Superintendencia de Educación. En palabras del presidente "Estas dos instituciones contemplan un conjunto de nuevas 
herramientas y estándares de calidad, que promoverán el mejoramiento continuo de la calidad de los establecimientos educacionales, estableciendo pisos mínimos y consecuencias para aquellos que no los alcancen, nuevas evaluaciones en terreno a los procesos de los establecimientos y nuevos mecanismos de apoyo directo desde el Ministerio a los procesos técnico pedagógicos" (Ministerio de Educación 2011)

El Sistema de Acreditación, que se venía utilizando desde el gobierno de Ricardo Lagos, es sometido a evaluaciones externas. En esta línea, se constituyen instancias de mayor vigilancia que permitan distinguir entre establecimientos con o sin calidad. Lo mismo ocurre a nivel de educación superior, donde se creará la Superintendencia de Educación Superior "que garantice la rendición de cuentas y la transparencia de todas las instituciones de educación superior, mejorando la información, fortaleciendo la fiscalización y adoptando las medidas necesarias para un adecuado cumplimiento de la legislación vigente" (ibíd.).

En esta misma dirección, "el Ministerio efectuará una evaluación externa a todo el sistema de aseguramiento de la calidad de la educación superior, que incluya tanto al sistema de acreditación, como a sus demás componentes" (ibíd.). Por tanto, la desmunicipalización permite la incorporación de profesionales seleccionados mediante el Sistema de Alta Dirección Pública y la integración de representantes de la comunidad local y del Ministerio de Educación. Otro cambio sustantivo con respecto a las regulaciones de gobiernos anteriores es el traspaso del financiamiento desde los Bancos al mismo Estado como garante del Crédito Estatal. El Estado entonces, deja de ser solamente un aval y pasa a asumir la responsabilidad directa del financiamiento crediticio como una manera de enfrentar la administración de la calidad educativa a través del mercado.

\section{c) Observación de los movimientos de protesta}

Desde las observaciones del Estado, la semántica del movimiento de protesta (principalmente orientada a poner fin al lucro) se condiciona mediante la presencia o ausencia de calidad en los distintos proyectos educativos establecidos por ley. Al igual que en el periodo analizado previamente, se reconoce la preponderancia de incorporar temáticas relacionadas con el mejoramiento de la calidad en la educación y fiscalizar establecimientos que se desentiendan de su función pedagógica. No obstante, el gobierno señala que las demandas del movimiento deben adaptarse a fines pragmáticos, de modo que el real peligro de los movimientos de protesta sería su progresiva tendencia hacia la intransigencia o incapacidad de reflexionar por sí mismos acerca de otras necesidades del país que deben ser cubiertas por el sistema político, como son la extrema pobreza, la salud o la vivienda.

En este mismo sentido, se cuestiona la representatividad vinculante de sus demandas, aludiendo a sectores no representados en las marchas, cuyas posturas deben conciliarse. Se establece, por ejemplo, la gratuidad como enemigo de la libre competencia en base a la calidad, bajo la que el gobierno no estaría dispuesto a ceder. A la luz de estas observaciones por parte del Estado, el movimiento carecería de la reflexividad suficiente respecto a sus propias demandas, volviéndose intransigente ante las propuestas del gobierno. Entre otras cosas se destaca que no se tiene en cuenta lo limitado de los recursos y que la ideologización del movimiento estudiantil impide establecer demandas racionales frente a esta realidad.

En este periodo se generan hitos relevantes con respecto a los movimientos de protesta, en cuanto a la emergencia del movimiento social por la educación, el que ha sido transversal en el tiempo. La implementación de un cambio en la Tarjeta Nacional Estudiantil (TNE), en cuanto a la restricción de su uso, fue un intento de reforma que dio inicio al movimiento estudiantil en el primer semestre del año 2011 . El procesamiento ha sido complejo, ya que las peticiones del movimiento estudiantil atacan directamente la 
organización, en cuanto se exige el fin de la subsidiariedad y una vuelta al Estado de Compromiso, es decir un Estado garantista de ciertos derechos considerados como basales o fundamentales.

\section{d) Concepto de libertad}

En términos generales, las medidas del aparato público se condicen con el libertinaje económico, es decir, aquel que reproduce condiciones jerárquicas ajenas a la racionalidad pedagógica a la hora de ejercer la libertad de enseñanza. El énfasis de las expectativas económicas, con respecto a las utilidades generadas por el mercado educativo, establece un elemento central: se interviene la Universidad del Mar. Nunca antes se había realizado una acción que interviniera en algún grado una institución que poseyera autonomía jurídica y económica.

El libertinaje económico, creado por los grupos que reivindican la libertad de enseñanza, como eje central en todas las actividades pedagógicas, genera un desborde dentro del aparato educativo y un conflicto en la operatividad del Estado, ya que no se poseen las atribuciones necesarias para la intervención, en el contexto en que una institución educativa abandona flagrantemente su estatuto educativo. Si bien los preceptos están claramente definidos, como el aseguramiento de la calidad, no se poseen las atribuciones pertinentes para responder en consonancia con éstos.

La desregulación total, o un sistema de aseguramiento corruptible como la Comisión Nacional de Acreditación (CNA), resultan contraproducentes cuando las lógicas del mercado vuelven inconducentes la propia actividad educativa o pedagógica. Este es el marco que constituye la amenaza a la libertad. A partir de este momento, se generan nuevas reformas, se completan o generan atribuciones en el Ministerio de Educación y su figura ejecutiva. Estas apuntan a un grado necesario de regulación frente al patente libertinaje económico en el sistema educativo, en orden a proteger el precepto axiomático de la libertad de enseñanza.

De esta manera, la amenaza al concepto de libertad en este periodo, basado en el libertinaje económico, está relacionado con la saturación que se ha hecho del argumento de no regulación o no intervención en ámbitos donde prima o debe primar la libertad. Es la saturación del mismo precepto de libertad lo que genera restabilizaciones semánticas de libertinaje económico, que producen amenazas a la libertad de enseñanza.

En función de lo anterior, la siguiente tabla resume los principales nodos argumentativos recién presentados.

Tabla 4: Gobierno de Sebastián Piñera (2010- Actualidad)

\begin{tabular}{|c|c|c|c|}
\hline $\begin{array}{c}\text { Expectativas en } \\
\text { torno al Estado }\end{array}$ & $\begin{array}{c}\text { Regulaciones } \\
\text { estatales }\end{array}$ & $\begin{array}{c}\text { Observación de los } \\
\text { movimientos de } \\
\text { protesta }\end{array}$ & $\begin{array}{c}\text { Concepción de } \\
\text { libertad }\end{array}$ \\
\hline $\begin{array}{c}\text { Asegurar } \\
\text { condiciones } \\
\text { mínimas de } \\
\text { financiamiento e } \\
\text { información }\end{array}$ & $\begin{array}{c}\text { Instancias de } \\
\text { regulación de las } \\
\text { propias } \\
\text { regulaciones } \\
\text { (estándares) }\end{array}$ & $\begin{array}{c}\text { Valorización de la } \\
\text { movilización/ } \\
\text { ideologización }\end{array}$ & $\begin{array}{c}\text { Libertad/libertinaje } \\
\text { económico }\end{array}$ \\
\hline
\end{tabular}

Fuente: Elaboración propia

\section{Reflexiones Finales}

En base a los lineamientos que han guiado el presente análisis, establecemos como primado de nuestra reflexión los alcances que ofrece la sedimentación generada a partir 
del devenir operativo del Estado, en tanto dicho procedimiento se encuentra imbricado a las reformas acontecidas en los periodos seleccionados, y a su respectivo condicionamiento histórico. En tal sintonía, identificamos la emergencia de una idea de libertad que funge como una constante, en la medida que se articula como un principio permanentemente amenazado por el surgimiento de irritaciones contingentes, provenientes del entorno.

A la luz de dichos antecedentes, colegimos que las posibilidades de restabilización cambio en las regulaciones estatales- en las estructuras de expectativas del Estado, evidencian la configuración de una noción de libertad negativa, disociada de cualquier impronta axiológica, e incluso, peyorativa, sino más bien, como la "inexistencia de obstáculos, barreras o restricciones, y en la posibilidad de actuar en la ausencia de estas" (Carter 2010: 16). De acuerdo a lo mencionado, esta concepción negativa se encuentra íntimamente relacionada con la autodeterminación individual que fundamenta a las sociedades liberales ${ }^{3}$. No obstante, cabe señalar que, a pesar del tránsito enmarcado entre el régimen dictatorial encabezado por Augusto Pinochet hasta los gobiernos de Bachelet y Piñera, se observa una continuidad en la idea de libertad negativa, más allá de las cambios estructurales que supondría la codificación democrática de los dos últimos periodos aludidos. De este modo, la transición democrática, marcada por la apertura del Estado al procesamiento de las comunicaciones originadas desde los movimientos de protesta y el término de la persecución ideológica y armada contra los grupos disidentes, no emergen como factores relevantes que logren desestabilizar el núcleo duro de la libertad negativa.

En orden a establecer una línea de base, postulamos que la libertad negativa, desde una perspectiva anclada a la evolución sociocultural, opera como un basamento estructural que le otorga soporte, y un margen de plausibilidad, a las variaciones semánticas en los distintos periodos seleccionados.

Desde este encuadre analítico, el primer periodo del Régimen Militar (1973-1980), da cuenta de un quiebre institucional que impregnó las estructura de expectativas vigentes hasta el gobierno de Salvador Allende. Tal punto de inflexión se vio constituido en la idea de libertad que pregonaban las Fuerzas Armadas, la que se garantizó mediante la promulgación de leyes, decretos, normas y reglamentos encaminados a cristalizar la introducción de valores nacionales como la justicia e igualdad ante la ley, principios considerados ausentes durante el gobierno de la Unidad Popular. En términos generales, sostenemos que las autodescripciones generadas por el Estado en dicho contexto, tienden a graficar un desajuste entre las transformaciones estructurales llevadas a cabo y los recursos semánticos que se utilizaron para su consecución. A modo de ejemplo, resulta muy ilustrativo emplear la situación de divergencia entre la producción discursiva, a nivel de documentos oficiales, que versaba sobre un orden jurídico respetuoso de los derechos humanos, en condiciones que la violación de éstos mismos era conducida por el aparato público en todas sus fases.

En el segundo periodo del régimen militar, la libertad negativa funge como un eje axiomático, la base de la organización de la sociedad operativizada a través de la constitución de 1980, donde el lado marcado de la forma - en la semántica de la libertad negativa- opera en su lado no marcado cuatro principios que van a establecer la organización del sistema. 1) El principio de derecho anclado en normas jerárquicas contenido en el derecho natural, 2) El gobierno subsidiario donde el peso de los logros descansa en el mérito individual; 3) El libre mercado como mecanismo para alcanzar los objetivos de justicia, libertad, prosperidad, para todos en la medida de sus capacidades y

\footnotetext{
${ }^{3}$ A diferencia de su versión positiva, que implica la autodeterminación colectiva, reflejada principalmente en el estatismo o socialismos reales (Berlin 1988).
} 
esfuerzos; 4) El progreso espiritual que identifica valores, principalmente familiares para el crecimiento de la persona humana.

En el primer principio, subyace la determinación jurídica - contractual de lo que se entiende por humano. En este sentido, las interrelaciones de lo humano operan, en este contexto, a través del concepto de la libertad negativa. Las relaciones no pueden ser determinadas por el Estado, sino en función de las propias personas como entes individuales. Por lo tanto se estructura una subordinación del Estado ante la libertad de enseñanza.

En el segundo principio, el Estado restringe su capacidad de acción e interviene solo cuando éstos se ven desprotegidos o impedidos de autorrealizarse a un nivel aceptable, pero nunca total. Por lo tanto, existe un posicionamiento social en base al esfuerzo individual.

En el tercer principio, el mercado opera como el espacio de reticulación donde se expresan los dos principios anteriores: por una parte en la libertad de elección y por otra alcanzar el éxito individual. En esta relación, de la elección y el éxito se pretende asegurar la calidad de la educación a través del mercado. El último principio, la función del progreso espiritual es inherente a la identificación de valores que se adecúan a la propia construcción del proyecto de sociedad, por lo tanto es a través de los valores familiares, especialmente católicos, donde se encuentra la verdadera preparación del individuo. Por lo tanto, la familia adquiere un rol protagónico como generadora de competencias en la sociedad.

Los principios operan desde la opacidad como semánticas en una forma de dos lados donde en el lado marcado se encuentra la noción de libertad negativa y que corresponde al elemento basal en la organización del sistema desde la selección y restabilización de la semántica en los inicios del régimen, a modo de ideal fundacional, y la operacionalización de la semántica a través de la constitución de 1980. No obstante esta forma de organización ha sido amenazada durante cada periodo histórico descrito anteriormente en la distinción de libertad/libertinaje moral y político; libertad/autoamenaza - donde el propio Estado, en la forma autoritaria de su operar, ha reintroducido inestabilidad al sistema- ; libertad/calidad subordinada al pago y libertad/libertinaje económico.

Los movimientos de protesta se han constituido entonces, como la principal irritación, a modo de fiscalización, en la organización del Estado. En la lógica de este último, la organización en base a la libertad negativa ha estructurado regulaciones que han sido irritadas y modificadas por el Estado en cada periodo histórico. Este, ha introducido en su estructura las variaciones que le permiten seguir operando con la semántica condensada de la libertad negativa, pero sin modificar su organización. De esto se desprende que en los últimos gobiernos, si bien se modifican estructuras como el cambio de la LOCE (ley orgánica constitucional de enseñanza) a la LGE (Ley general de educación), el Estado no modifica su operacionalización organizacional. Los principios descritos en cada periodo siguen intactos.

Los movimientos de protesta actuales (periodo Bachelet- Piñera), respecto a la educación, han tratado de desmitificar los principios asociados a la libertad negativa.

1) Mito de la observancia del derecho: se desmitifica la naturalización de la desigualdad, ya que esta no es necesariamente natural, sino, pueden que existir condiciones estructurales que la regulan, por lo tanto, el rol del Estado es importante para ejercer parámetros de regulación de esta. 
2) Mito de la movilidad social: La educación ha fracasado en ser garante de la movilización social, pues, las capacidades no aseguran cruzar de un estrato social a otro.

3) Mito de la autorregulación: La concentración educativa a manos del mercado atenta la calidad y es la causa de la depresión educacional. En cuanto la calidad no satisface los requerimientos diseñados por el Estado no se va a cumplir los objetivos de justicia, libertad y prosperidad

4) Mito de la libre elección de las familias: La elección está determinada por condiciones mínimas. Una familia de escasos recursos, se ve constreñidas a elegir, por lo tanto opta por determinados centros educacionales.

De acuerdo a lo anterior, el rol del Estado ha sido monolítico desde la instauración de la institucionalidad liberal plasmada en la constitución de 1980, es decir, en el periodo de Pinochet, Piñera y Bachelet este ha operado de manera compensatoria lo que se ha descrito como Estado de carácter subsidiario.

Se ha atribuido a las lógicas de decisión estatal un principio de pragmatismo exacerbado, alejando completamente el principio republicano que supone una institucionalidad democrática. Sin embargo, la subsidiariedad nunca ha cumplido con una verdadera función compensatoria en la carencia que emana de la natural diferencia entre los individuos. La operatividad real del Estado está relacionada con un objetivo despolitizador de áreas importantes de la sociedad y fundamentalmente dar las condiciones necesarias para que las lógicas de mercado regulen la gestión y oferta educativa, las aseguradoras de fondos de pensión (AFP) y de salud entre otras esferas importantes del funcionamiento social y que constituyen parte de su legislación orgánica, esto es, la constitución no puede operar sin las leyes que regulan estos aspectos y por tanto, los quórums más altos son aquellos relacionados directamente con la organización de la constitución.

Si bien ha existido durante mucho tiempo motivaciones explícitas para cambiar estos aspectos de la operatividad estatal, ha sido imposible dada la planificación y estructuración de la constitución de 1980. Esta última no permite adoptar posiciones ajenas a las que el sector que la impuso, aun cuando gobierne una administración que pretenda generar un cambio. Esta forma de constreñir las decisiones en la administración gobernante, es lo que ha dado lugar a lógicas monolíticas en el funcionamiento del Estado y su imposibilidad para generar cambios por vía institucional en cada uno de los periodos a excepción del primer periodo de Pinochet donde se verificaba el Estado de excepción en la medida que la constitución de 1925 estaba suspendida.

El tiempo de conocimiento y entendimiento del funcionamiento del sistema electoral binominal, como lógica regulatoria, ha sido bastante largo, lo que ha permitido que opere sin mayores objeciones. Sin embargo, actualmente se han develado sus lógicas y fundamentalmente las motivaciones y objetivos, que han sido expuestas de manera explícita por sus ideólogos: impedir cualquier decisión que implique modificar el andamiaje liberal y sus instituciones.

Por ello, las expectativas del Estado, de cada periodo histórico, ha sido la mantención de la organización devenida en una invariabilidad social tematizada e irritada por los movimientos de protesta reintroduciendo nuevas variaciones semánticas, de derechos, en la ciudadanía que se escinde de la organización estatal en cuanto a las regulaciones ya establecidas. Un cambio de organización del Estado, en cuanto a las expectativas de estabilidad, va a depender de cómo este procese las irritaciones de la ciudadanía operativizada fundamentalmente en la semántica de la asamblea constituyente, aun cuando esta carece de probabilidades de ser institucionalizada. Por ello, la gran problemática entre la expectativa del Estado y la ciudadanía es que las decisiones 
vinculantes colectivamente operan escindidamente, acopladas al sistema binominal, que a su vez opera parasitariamente. RM

\section{Bibliografía}

Arriagada, G. (1981). El pensamiento político de los militares. Santiago de Chile: CISEC Assaél, J., Cornejo, R., González, J., Redondo, J., Sánchez, R. \& Sobarzo, M. (2011). La empresa educativa chilena. Educação \& Sociedade, 32(115), 305- 322.

Berlin, I. (1988). Dos conceptos de la idea de libertad. Santiago de Chile: Editorial Universitaria.

Blanco, J. (2011). Observando la historia de las ideas. Niklas Luhmann y su contribución al debate contemporáneo de las ciencias históricas. Revista Politeia, 47(34), 141- 170.

Briones, G., Castro, E., Delpiano, A., Echeverría, R., Edwars, V., Gajardo, M., Gazmuri, C., González, L., Hevia, R., Latorre, C., López, G., Magednzo, A., Magendzo, S. \& Núñez, I. (1991). Las transformaciones de la educación bajo el régimen militar (Volumen I). Santiago de Chile: Programa interdisciplinario de investigaciones en educación.

Briones, G., Castro, E., Delpiano, A., Echeverría, R., Edwars, V., Gajardo, M., Gazmuri, C., González, L., Hevia, R., Latorre, C., López, G., Magednzo, A., Magendzo, S. \& Núñez, I. (1991). Las transformaciones de la educación bajo el régimen militar (Volumen II). Santiago de Chile: Programa interdisciplinario de investigaciones en educación.

Carter, I. (2010). Libertad negativa y positiva. Revista Astrolabio, 1(10).

Guillaudat, P. \& Mouterde, P. (1998). Los movimientos sociales en Chile: 1973-1993. Santiago de Chile: LOM.

Guzmán, J. (1980). La definición constitucional. Revista Realidad, 3. Fundación Jaime Guzmán.

Guzmán, J. (1982). El sentido de la transición. Revista Realidad, 38. Fundación Jaime Guzmán.

Latorre, C., Núñez, I., González, R. \& Hevia, R. (1991). La municipalización de la educación: Una mirada desde los administradores del sistema. Santiago de Chile: Programa interdisciplinario de investigaciones en educación.

Luhmann, N. \& De Georgi, R. (1993). Teoría de la sociedad. México D.F.: Universidad Iberoamericana.

Luhmann, N. (1991). Sistemas sociales. Lineamientos para una teoría general. México D.F.: Alianza Universidad.

Luhmann, N. (2007). La sociedad de la sociedad. México D.F.: Herder.

Núñez, I. \& Vera, R. (1988) Organizaciones de docentes, políticas educativas y perfeccionamiento. Santiago de Chile: Programa interdisciplinario de investigaciones en educación.

Retamozo, M. (2009). Las demandas sociales y el estudio de los movimientos sociales. Cinta Moebio, 35, 110- 127.

Santa Cruz, E. \& Olmedo, A. (2012). Neoliberalismo y creación de 'sentido común': Crisis comunicativa y medios de comunicación en Chile. Profesorado, 16(3), 145- 168.

Stäheli, U. (2000) Sinnzusammenbrüche. Eine dekonstruktive lektüre von Niklas Luhmann systemtheorie. Göttingen: Velbrück Wissenschaft.

Vial, G. (1998). Análisis crítico del régimen militar. Santiago de Chile: Editorial Universitaria.

Villalobos- Ruminott, S. (2008). Modernidad y dictadura en Chile: La producción de un relato excepcional. A contracorriente, 6(1), 15- 49.

Willke, H. (2006). La transformación de la democracia como modelo de orientación de las sociedades complejas. Estudios Públicos, 102, 179- 201. 


\section{Fuentes de Internet:}

De la Cruz, P. (2006). La educación formal en Chile desde 1973 a 1990: Un instrumento para el proyecto de nación. Consultado el 18 de mayo, 2013, desde http:// halshs.archives- ouvertes.fr/ docs/00/10/42/82/PDF/P_CRUZ.pdf

Diario EMOL. Discurso 21 de mayo de 2006. Consultado el 31 de mayo, 2013, desde http:// www.emol.com/noticias/documentos/pdfs/discurso_21_mayo_06.pdf

Diario La Nación. Educación: vea el tercer plan del Gobierno y todas las propuestas. Consultado el 31 de mayo, 2013, desde http://www.lanacion.cl/educacion- vea- eltercer- plan- del- gobierno- y- todas- las- propuestas/ noticias/2011- 0818/095901.html

Diario La Tercera. Presidente Sebastián Piñera propuso un gran acuerdo nacional por la educación. Consultado el 31 de mayo, 2013, desde http:// www.latercera.com/ noticia/ politica/2011/07/674- 377649- 9- presidentesebastian- pinera- propuso- un- gran- acuerdo-nacional- por- la- educacion.shtml

Fundación Jaime Guzmán. Propuesta del Gobierno en Educación. Consultado el 31 de mayo, 2013, desde http:// www.udi.cl/ website/ content/galeria/TPENQBFQAFW]ZIPIOCDF/Agendaaldia_7. pdf

Fundación Jaime Guzmán. La Transición y el Futuro del País. (1982). Consultado el 16 de mayo, 2013, desde http:// www.jaimeguzman.cl/wpcontent/ uploads/documentos/ entrevistas/opiniones- la- transicion- y- el- futuro- delpasi.pdf

Gobierno de Chile (1974). Declaración de Principios del Gobierno de Chile. Consultado el 16 de mayo, 2013, desde http:// www.archivochile.com/Dictadura_militar/doc_jm_gob_pino8/DMdocjm0005.p $\underline{\mathrm{df}}$

Gobierno de Chile (1974). Mensaje Presidencial: 11 septiembre 1973 - 11 de septiembre 1974: S.E. el Presidente de la República General de Ejército Augusto Pinochet Ugarte informa al país. Consultado el 16 de mayo, 2013, desde http:// www. memoriachilena.cl/temas/documento detalle.asp?id=MC0042488

Gobierno de Chile (1975). Mensaje Presidencial: 11 septiembre 1974 - 11 de septiembre 1975: S.E. el Presidente de la República General de Ejército Augusto Pinochet Ugarte informa al país. Consultado el 17 de mayo, 2013, desde http:// www.memoriachilena.cl/temas/documento_detalle.asp?id=MC0042489

Gobierno de Chile (1976). Mensaje Presidencial: 11 septiembre 1975 - 11 de septiembre 1976: S.E. el Presidente de la República General de Ejército Augusto Pinochet Ugarte informa al país. Consultado el 17 de mayo, 2013, desde http:// www.memoriachilena.cl/temas/documento detalle.asp?id=MC0042490

Gobierno de Chile (1977). Mensaje Presidencial: 11 septiembre 1976 - 11 de septiembre 1977: S.E. el Presidente de la República General de Ejército Augusto Pinochet Ugarte informa al país. Consultado el 17 de mayo, 2013, desde http:// www.memoriachilena.cl/temas/ documento_detalle.asp?id=MC0042491

Ministerio de Educación (2011). Políticas y propuestas de acción para el desarrollo de la educación chilena. Consultado el 31 de mayo de 2013, desde http:// www.mineduc.cl/ usuarios/ mineduc/ doc/201108011945470.DocumentoAgost o2011.pdf

Radio Cooperativa. Los detalles de la última propuesta del gobierno para aprobar el Presupuesto en Educación. Consultado el 31 de mayo, 2013, desde http:// www.cooperativa.cl/ los- detalles- de- la- ultima- propuesta- del- gobierno- paraaprobar-el-presupuesto- en- educacion/prontus nots/2011-11-23/092132.html

Tolerancia cero (2012). Entrevista al presidente de la republica Sebastián Piñera sobre el caso de la comisión nacional de acreditación (CNA). Consultado el 20 de mayo, 2013 desde http:// www.chilevision.cl/ home/ content/ view/444895/229/ 


\section{Anexo Metodológico}

En relación a los documentos que fueron seleccionados para el análisis del presente artículo, podemos indicar las siguientes fuentes:

Documentación Oficial:

Mensaje Presidencial - 11 de septiembre de 1973, Versión electrónica, Biblioteca Nacional de Chile.

Mensaje Presidencial - 11 de septiembre de 1974, Versión electrónica, Biblioteca Nacional de Chile.

Mensaje Presidencial - 11 de septiembre de 1975, Versión electrónica, Biblioteca Nacional de Chile.

Mensaje Presidencial - 11 de septiembre de 1976, Versión electrónica, Biblioteca Nacional de Chile.

Mensaje Presidencial - 11 de septiembre de 1977, Versión electrónica, Biblioteca Nacional de Chile.

Mensaje Presidencial - 11 de septiembre de 1978, Versión electrónica, Biblioteca Nacional de Chile.

Declaración de Principios de la Junta Militar, 1974, Versión Electrónica, Archivo Chile.

Prensa y Periódicos:

El Mercurio, Santiago, 1973, Biblioteca Nacional de Chile.

El Mercurio, Santiago, 1974, Biblioteca Nacional de Chile.

El Mercurio, Santiago, 1975, Biblioteca Nacional de Chile.

El Mercurio, Santiago, 1976, Biblioteca Nacional de Chile.

El Mercurio, Santiago, 1977, Biblioteca Nacional de Chile.

El Mercurio, Santiago, 1978, Biblioteca Nacional de Chile.

El Mercurio, Santiago, 1979, Biblioteca Nacional de Chile.

El Mercurio, Santiago, 1980, Biblioteca Nacional de Chile.

La Nación, Santiago, 1973, Biblioteca Nacional de Chile.

\section{Sobre los autores}

Felipe Rivera es investigador en la Vicerrectoría de Investigación y Desarrollo, Universidad de Concepción, Chile. Sociólogo por la Universidad de Concepción, Chile. Entre sus líneas de investigación se encuentran: Teoría de Sistemas Sociales; Fenomenología y Etnometodología; Análisis Conversacional; Sociología de la Familia; Estudios Postcoloniales; Pedagogía Crítica.

felirivera@udec.cl

Jorge Cárcamo es estudiante de Magíster en Análisis Sistémico Aplicado a la Sociedad, Universidad de Chile. Licenciado en Historia por la Universidad de Chile. Entre sus líneas de investigación se encuentran: Historia Política; Teoría de Sistemas Sociales.

jorgecarcamo2009@gmail.com

Carlos Carrasco, Facultad de Ciencias Sociales de la Universidad de Concepción. Licenciado en Sociología por la Universidad de Concepción, Chile. Entre sus líneas de investigación se encuentran: Teoría de sistemas sociales, Sistemas Organizacionales, Estudios Postcoloniales.

carloscarrasco@udec.cl

José Miguel Hoyos, Facultad de Ciencias Sociales de la Universidad de Concepción. Licenciado en Sociología por la Universidad de Concepción, Chile. Entre sus líneas de investigación se encuentran: Estudios Postcoloniales, Imaginarios sociales, Estudios Subalternos.

joshoyos@udec.cl 
Dusan Cotorás, Facultad de Ciencias Sociales e Historia, Universidad Diego Portales, Chile. Licenciado en Sociología por la Universidad Diego Portales, Chile. Entre sus líneas de investigación se encuentran: Teoría de sistemas, Educación.

dcotoras@gmail.com

Contacto

Víctor Lamas \#1290

Casilla 160- C

Concepción, Chile

Código Postal: 4070386

Recibido: Julio 2013

Aceptado: Agosto 2013 